\title{
Hydrogen Through Water Electrolysis and Biomass Gasification for Application in Fuel Cells
}

\author{
${ }^{1}$ Y. Kiros, ${ }^{2}$ S. Marini, ${ }^{2}$ M. Villa and ${ }^{2}$ P. Nelli \\ ${ }^{1}$ Department of Chemical Engineering \& Technology, KTH Royal Institute of Technology, SE-100 44 Stockholm, \\ Sweden \\ ²Dipartmento di Progettazione e Tecnologie, Univeristà di Bergamo, Viale Marconi 5, 22044, Italy \\ yohannes@kth.se
}

\begin{abstract}
Hydrogen is considered to be one of the most promising green energy carrier in the energy storage and conversion scenario. Although it is abundant on Earth in the form of compounds, its occurrence in free form is extremely low. Thus, it has to be produced by reforming processes, steam reforming (SR), partial oxidation (POX) and autothermal reforming (ATR) mainly from fossil fuels for high throughput with high energy requirements, pyrolysis of biomass and electrolysis. Electrolysis is brought about by passing electric current though two electrodes to evolve water into its constituent parts, viz. hydrogen and oxygen, respectively. Hydrogen produced by non-noble metal catalysts for both anode and cathode is therefore cost-effective and can be integrated into fuel cells for direct chemical energy conversion into electrical energy electricity, thus meeting the sustainable and renewable use with low carbon footprint.
\end{abstract}

\section{INTRODUCTION}

Environmentally benign fuels, which can replace today's fossil based fuels, such as gasoline, oil and coal for combustion either in stationary or mobile applications is of utmost importance. One such fuel is hydrogen, which is considered to be the fuel of the future. Hydrogen is an energy carrier maintaining potential applications in many industrial processes such as fertilizers, petroleum refineries, food processing, bulk and specialty chemicals as well as power generation. Hydrogen plays an important role as a potential fuel for aviation, vehicles and domestic heating requirements either by direct combustion or in the so-called "cold combustion" as in fuel cells. Large scale introduction of hydrogen would mean a paradigm shift as a renewable energy carrier, leading to a substantial decrease of the greenhouse gases. Owing to its abundance in the form of compounds and complexes, it is estimated that over $75 \%$ of the 164 mass of the universe is primarily hydrogen (1). The combustion product of hydrogen practically being water makes it to be highly important for clean and sustainable energy production. Since hydrogen is energy rich on weight basis ( $120 \mathrm{MJ} / \mathrm{kg}$ ) compared to gasoline $(44.4 \mathrm{MJ} / \mathrm{kg})$ but poor on volumetric basis, large volumes of hydrogen has to be stored, handled and transported for application for example in vehicles with internal combustion engines or fuel cells. Therefore one of the daunting challenges for the introduction of hydrogen as a fuel is to find a safe method with high storage capacity and facile generation of the fuel, providing high energy efficiency, light weight and volume, predictable performance, fuel purity and economy.

\section{HYDROGEN PRODUCTION}

Global hydrogen production is estimated to be 50 million tons annually $(2,3)$, where the main feedstock are fossil fuels, such as natural gas, hydrocarbons and coal. These processes are highly endothermic, implying high temperatures $(>800 \mathrm{oC}$ ) and moderate pressures (20-30 bar), where a set of reaction steps such as desulfurization, high and low temperature shift reactions, methanation and adsorption are required for high purity hydrogen. Due to the carbon content contained in the fossil fuels, there is a stoichiometric emission of carbon and thereby increasing the concentration of greenhouse gases (GHG) to the atmosphere. Thus, electrochemical process of water splitting (electrolysis), where hydrogen in the cathode and oxygen in the anode are released is a sustainable solution, if electricity is generated from renewable energy resources.

The benefit of finding robust, stable and active electrocatalysts instead of the noble metals, which are scarce and highly expensive is a challenge for the production of hydrogen as a "green energy" source 
for application in industrial processes and fuel cells. Demand and supply constraints of Ru, Ir and Pt and platinum group metal alloys for application in largescale electrolyzers would mean a decrease of the loadings by several factors and keeping intact the catalytic activity. Thus, there is a growing interest in replacing these electrocatalysts by non-precious and ample reserves of the transition metals. Herein we report the sponge-like and highly porous with significant surface area of the $\mathrm{Ni}$-Al alloys leached out by $\mathrm{KOH}$ for this purpose. Two different electrochemical reactions for cathodic (hydrogen evolution) and anodic (oxygen evolution) configurations were studied by applying alloys of Raney-Ni catalysts, albeit with different compositions and doped with other metallic species. The gas diffusion electrodes (GDE), wet-proofed by PTFE were prepared by the rolling method in thicknesses of 0.5-07 $\mathrm{mm}$ and then tested in $6 \mathrm{M} \mathrm{KOH}$ at $60-80 \mathrm{oC}$, where their polarization curves were assessed in durability tests. The role of catalyst additives is significant for lowering the overpotentials and the intrinsic activities of the respective electrodes to be able to serve for prolonged performances in alkaline electrolyzers.

\section{FUEL CELLS FOR ELECTRIC GENERATION}

The high efficiency, high power density, flexibility in size and installation area as well as environmentally friendliness of the fuel cells make them an attractive and alternative power sources for tractionary, portable, hybrid and stationary applications. There are five main types of fuel cells, which have the common advantages but yet are contending in cost, access in materials, performance and stability. Although the pros and cons of each type of fuel cell are to a large extent specific to the materials, electrolyte, operation temperature, purity or impurity of the oxidant, there are however, major distinguishing marks among them. Common to all fuel cells is, however the electrochemical oxidation of hydrogen at the anode and reduction of oxygen at the cathode resulting in the in the generation of electricity and heat as well as water.

The low temperature fuel cells, especially polymer membrane electrolyte fuel cell (PEMFC) and alkaline fuel cell (AFC) have both a relatively fast start-ups mainly due to the temperature regime in which they operate. PEMFC has shown high current densities and small weight and compact stacks due to the incorporation of the electrolyte in the polymer matrix. Not excepting that the noble metal price is high and less accessible for mass application in fuel cells, the loss of the activity is ascribed to the agglomeration and corrosion of the catalyst particles and hence decrease of the surface areas. The phosphoric acid (PAFC) as an intermediate temperature fuel cell was a frontrunner during the 80 s and 90 s but due to high loadings of platinum group metals as catalyst, this fuel cell has been phased out. The molten carbon fuel cell (MCFC) and solid oxide fuel cell (SOFC) operate at 500-600 oC and 900-1000 oC, respectively, both requiring robust materials and thermal stability.

Previous work (4) with wood charcoal and agroresidues of a producer gas integrated with fuel processing and gas clean-up laboratory demonstration unit (LDU) showed a successful production of hydrogen for operation in a $250 \mathrm{~W} \mathrm{AFC}$ system. The integrated system was composed of a gasifier to generate producer gas, hydrogen enrichment through high temperature and low temperature shift reactors, gas cleaning units (sulfur, carbon dioxide and oxygen) and preferential oxidation of carbon monoxide. The hydrogen produced after the gasifier, having $3-6 \%$ vol.\% after these steps increased to $20-30$ vol.\% to be fed to the fuel cell. Electrical efficiency from material and energy balances for the system producer gas to the AFC generator, based on lower heating value of wood to direct current was found to be $29 \%$. Thus, the study showed that biomass gasification/pyrolysis can be integrated for production of electricity both in decentralized or as stand-alone fuel cell power generators.

\section{REFERENCES}

[1] Contreras, J. Capiro, M. Molero, T. N. Verziroglu, Int. J. Hydrogen Energy, 24 (1999) 1041.

[2] C. R. Ewan, R. W. K. Allen, Int. J. Hydrogen Energy, 30 (2005) 809.

[3] Report of the hydrogen production expert panel, US DOE, Washington DC, 20585, 2013.

[4] Y. Kiros, C. Myrén, S. Schwartz, A. Sampathrajan, M. Ramanathan, Int. J. Hydrogen Energy, $\quad 24 \quad$ (1999) 549. 